\title{
Interactive comment on "Stable isotope investigation of groundwater recharge in the Carpathian Mountains, East-Central Europe" by Carmen-Andreea Bădăluţă et al.
}

\section{Carmen-Andreea Bădăluţă et al.}

carmenbadaluta@yahoo.com

Received and published: 25 April 2018

We would like thank the referee for the fast response and to the recommendations and we are grateful for the comments on how it can be further improved. We provide below a general response to the reviewer's comments/suggestions.

Comment: The paper's title and introduction suggest that it is a recharge study; however, that is probably the least discussed of the material in the paper. The only text that pertains to recharge is at the end of section 5.2 (page 11, lines 11-23) where the main conclusions appear to be that there are few discernible patterns in the stable isotopes and this implies that the groundwater is recharged locally and may be around six

Printer-friendly version

Discussion paper 
months old. The first point is self-evident - recharge is always a local process, what the authors may mean is that there has been little mixing in the aquifers subsequent to recharge (although there is little data presented to test that). The assumptions behind the approximate residence time are also not justified and it is speculative. The text in this section (page 11, lines 19-23) are also contradictory. To estimate the residence times or to understand the sources of water using geochemistry, there needs to be little or no mixing in the aquifers. The statement that there is "slow underground flow on the same direction of the aquifer" seems to imply that local recharge is mixed with laterally-flowing groundwater, which would not allow the geochemistry to be used in this way. There is also insufficient detail on the hydrogeology. Specifically, - the flow systems are not defined - there is no indication of where the recharge areas are (Fig. 1 show many of the wells to be located in valleys, are these really in discharge areas?) - there is no indication of wells depths, water table levels etc. If one wishes to sample recharge in wells, they need to be screened at the water table. - the only mention of methodology relating to the groundwater is actually "The spatial variability of stable isotopes in groundwater was spatially mapped using the ordinary kriging method (Nas and Berktay, 2010)." - 157 groundwater samples are mentioned in the abstract, but Table 2 list only 21 (and a similar number are on Fig. 3). If you are going to claim a large data set you need to present it and use it. The paper is mainly concerned with using stable isotopes to understand moisture sources. This is not really my field of expertise although I can follow the logic of the discussion. The authors would be better to cast the paper in that way with perhaps a sentence or two at the end stating that this is important information for understanding recharge or residence times in rivers etc. The paper is also very specific and there are no indications of how it relates to previous work on this topic in general or the region (there are papers by Bojar et al, 2017 and Bottyan et al., 2017 that look to cover similar topics). The conclusions also do not convey any general importance and it is not clear what a reader working on these topics elsewhere would get from the paper.

Response: We fully agree that the title and the general organization of the text do

Printer-friendly version

Discussion paper 
not clearly lead to the idea enounced in the title. We attempted a recharge study, the hypothesis being that we would be able to 1) disentangle between various moisture sources and tracks feeding precipitation in the study area and analyze their controlling factors, 2) track how precipitation water feeds local aquifers and 3) analyze the relationship between precipitation, river and ground waters; the overall aim being to provide policymakers a first tool to be used (and improved) to asses groundwater resources. There is a general lack of understanding in the region on how science can be put behind decisions - and we made an attempt to fill it. Nevertheless, the comments we have received have offered us a better "redline" to be followed towards achieving this goal and below we show how this will be used to improve the study and the paper. Thus, our article is now recast to address the points above. As such, we start with an improved description of the processes controlling the stable isotope composition of precipitation and continue with a thoroughly revised section on groundwater stable isotope geochemistry. This includes a better description of the local flow systems (with delineation of the recharge areas, description of the wells - depth, water table level and fluctuations, type of water usage removal - bucket vs. pump etc). Further, the text is directed towards linking the stable isotope composition of groundwater with that of precipitation and a discussion of the processes behind the variability in stable isotope composition in groundwater in relation with precipitation and rivers. We have separated the wells into two groups - located near the rivers and farther away - and discuss to what extent the exchange with river waters is seen in the stable isotope composition if groundwater and river water. We have attempted - and subsequently discarded - the calculation of isotope enabled mass balance as the data sets on discharge was very limited. As such, the paper now has a slightly different focus that makes a better use of the dataset we have, strengthening the conclusion, removing less-well supported claims and providing an assessment tool that could be used (and improved) for regions where similarly limited data sets are (or could be) obtained.

Interactive comment on Hydrol. Earth Syst. Sci. Discuss., https://doi.org/10.5194/hess-2018-6,

Printer-friendly version

Discussion paper 
2018.

HESSD

Interactive

comment

Printer-friendly version

Discussion paper

(c) (1) 